\title{
REDES DE SUPORTE SOCIAL AO ADOLESCENTE COM DIABETES MELLITUS TIPO 1
}

\section{SOCIAL SUPPORT NETWORKS FOR ADOLESCENT WITH DIABETES MELLITUS TYPE 1}

Marinês Finco

Judite Hennemann Bertoncini

\section{RESUMO}

Objetivo: Descrever as redes de suporte social que adolescentes com Diabetes Mellitus Tipo 1 (DM1) utilizam. Método: Pesquisa qualitativa realizada com dez adolescentes e familiares atendidos pelo Sistema Único de Saúde em Blumenau, de 6 de agosto a 16 de setembro de 2015. Dados coletados com entrevista aberta, observação e ecomapa. Resultados: A análise dos dados resultou em quatro categorias: relaçóes familiares, amizades, escolares e comunitárias. A família predomina como referência para os adolescentes. $\mathrm{O}$ apoio oferecido pela escola limitase à alimentação. Nas relaçôes comunitárias, a religião significa esperança de cura ou sensação de abandono. Conclusão: As redes de suporte social empoderam ou dificultam no enfrentamento da doença. Profissionais de saúde devem fortalecer as redes de suporte social para promover o autocuidado.

Palavras chaves: Adolescente. Diabetes Mellitus. Rede social.

\section{ABSTRACT}

Objective: To describe the social support networks that adolescent with Diabetes Mellitus Type 1 (DM1) used. Method: Qualitative research performed with ten 10 adolescents and family members attended by the Unified Health System in Blumenau, from August 6 to September 16, 2015. Data collected with open interview, observation and ecomap. Results: Data analysis resulted in four categories: family relationships, friendships, students relationships and community relationships. The family predominates as a reference for adolescents. The support offered by the school is limited to feeding. In community relationships, religion means hope for healing or a sense of abandonment. Conclusion: Social support networks empower or complicate the coping of disease. Health professionals should strengthen social support networks to promote self-care.

Keywords: Adolescent. Diabetes Mellitus. Social network.

\section{INTRODUÇÃO}

As redes de suporte social são estratégias encontradas pela família e pelo adolescente para auxiliar no enfrentamento após a descoberta do diabetes mellitus tipo (DM1). Rede é um conjunto formado por instituiçóes, grupos ou indivíduos e suas interconexóes, que pode ser uma fonte de oferecimento de apoio social, sendo que a quantidade e a qualidade do apoio variarão de acordo com as características estruturais e interativas da rede que o fornece ${ }^{(1)}$.

O ecomapa possibilita a representação das redes de suporte disponíveis do adolescente com sua família e de como ele identifica essa rede. No ecomapa, a pessoa ou os membros da família aparecem no

Enfermeira. Mestre em Saúde Coletiva. Universidade Regional de Blumenau.

Enfermeira. Doutora em Enfermagem. Universidade Regional de Blumenau. 
centro do círculo, os contatos da família com a comunidade, com pessoas e grupos significativos são representados nos círculos externos ${ }^{(2)}$.

Nesta perspectiva, este estudo objetiva descrever a rede de suporte social dos adolescentes portadores de DM1.

\section{MÉTODOS}

Este artigo é parte da pesquisa da dissertação de mestrado em saúde coletiva, de natureza qualitativa exploratória.

A pesquisa realizada nos serviços que atendem exclusivamente aos usuários do Sistema Único de Saúde (SUS) e constituem-se como a referência da atenção secundária para região do Médio Vale do Itajaí-MVI - SC, sendo eles a Policlínica de Especialidade e no Núcleo de Apoio ao Diabético (NAD) da Secretaria Municipal de Saúde de Blumenau, e a Policlínica Universitária (PU) da Universidade Regional de Blumenau (FURB), com 78 crianças e adolescentes cadastrados, totalizando $100 \%$ de atendimento ao SUS.

Participaram da pesquisa dez adolescentes com DM1 e dez familiares envolvidos diretamente nos cuidados ao adolescente. Os critérios de inclusão foram: ser adolescente portador de DM1; ter idade de 12 a 17 anos; ser atendido por um dos serviços de referência da regiáo da MVISC; ter diagnóstico de DM1 estabelecido há pelo menos um ano; aceitar participar da pesquisa. Foram excluídos todos os adolescentes que: não eram portadores de DM1; tinham menos de 12 anos ou mais de 18 anos; não eram atendidos por um dos serviços de referência da MVI-SC; com diagnóstico estabelecido há menos de um ano; não aceitaram participar do estudo; não tinham tempo e disponibilidade para participar da pesquisa.

Foi realizada uma entrevista aberta em profundidade com cada familiar e adolescente, e preenchimento do ecomapa com adolescente, vinculadas à consulta médica ou no domicílio, de 6 de agosto a 16 de setembro de 2015 pela pesquisadora responsável.
As entrevistas foram gravadas na íntegra, com a pergunta norteadora: Conte como você tem vivenciado o diabetes após descobrir que você/seu filho (a) tem a doença? Indagações sequenciais foram realizadas baseadas nas respostas dessa primeira pergunta, a fim de alcançar o objetivo da pesquisa.

A realização do ecomapa deu-se através do preenchimento pelo adolescente do desenho impresso após orientaçôes da pesquisadora. $\mathrm{O}$ adolescente se encontrava ao centro do ecomapa e os três círculos a sua volta conforme se distanciavam do centro representavam as relaçôes íntimas, as relaçôes pessoais e as relaçôes ocasionais. Esses círculos foram divididos nas categorias previamente definidas: relaçóes familiares, relaçóes de amizade, relações na escola/ trabalho e relaçôes comunitárias. $\mathrm{O}$ adolescente foi convidado a escrever nos círculos envoltos a ele os nomes das pessoas que faziam parte de suas relaçôes, conforme seus sentimentos e percepçóes e conforme o grau de proximidade dessas pessoas. Após o adolescente escrever nos círculos, a pesquisadora o questionava quem eram as pessoas no gráfico e escrevia na ficha de observação para posterior auxílio na análise do ecomapa. Abaixo modelo de ecomapa utilizado:

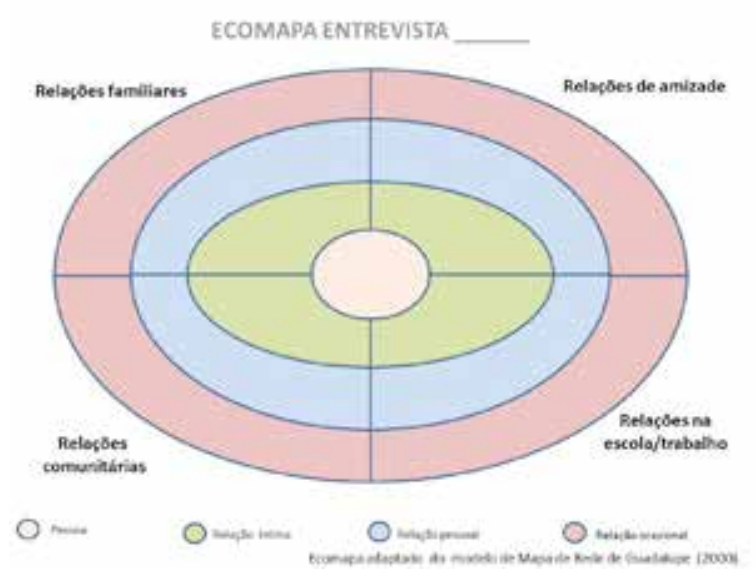

Figura 1: Ecomapa adaptado do modelo de Mapa de Rede de Guadalupe (2000).

Para a realização da análise do ecomapa foi realizada unificação das informaçóes em um único ecomapa, no qual anotou-se em cada 
círculo o número de pessoas que cada adolescente havia preenchido em seu ecomapa e o grau de parentalidade, em todas as relaçóes, exemplo: no círculo relação íntima na categoria relação família E1: escreveu o nome de sete pessoas, pais, avós, tios, padrinhos, professores e diretora e assim sucessivamente com todos os adolescentes. Posteriormente, realizado essa identificação para cada adolescente em cada círculo e em cada tipo de relação.

As observações de campo como postura, expressões de alegria, tristeza ou de angústia, foram anotadas na ficha de observação, logo após cada entrevista. A transcrição das entrevistas foi feita pela pesquisadora no dia da coleta e no dia seguinte, com a finalidade de manter a fidedignidade e abrangência das falas.

Para o tratamento dos dados procedeuse a análise de conteúdo. Cada entrevistado foi identificado pela letra $E$ e um número sequencial até $E 10$. O adolescente foi identificado pela letra $A 1$ sucessivamente até $A 10$. Definiu-se na ordem sequencial $E 8$ para o pai, E8ô para o avô e E8ó avó, respectivamente (os três participaram da entrevista). Após sucessivas leituras das entrevistas, realizamos a organização do material atendendo aos critérios de exaustividade, representatividade, homogeneidade e pertinência, constituindo o corpus a ser tratado. Ordenamos e agregamos esses dados conforme a similaridade das falas, resultando em quatro categorias: relaçóes familiares, relaçóes de amizades, relações escolares e relações comunitárias.

O projeto foi aprovado pelo Comitê de Ética da FURB com parecer No 1.124.736. A coleta dos dados iniciou após esclarecimento dos objetivos da pesquisa, garantia do anonimato, permitindo esclarecimento de dúvidas e após o aceite com assinatura do Termo de Consentimento Livre e Esclarecido para o adulto e para menores de 18 anos.

\section{RESULTADOS E DISCUSSÃO}

Descrevemos a seguir as redes de suporte identificadas pelos adolescentes ao realizar o ecomapa, dos resultados das entrevistas com adolescentes e seus familiares e da observação de campo.

\section{Relações familiares}

Com o diagnóstico do diabetes é inevitável que ocorram mudanças na vida familiar, todos mudam em função do adolescente com a doença. Com o início do tratamento, há uma desestruturação do equilíbrio familiar, havendo modificaçóes da rotina ${ }^{(3)}$, porém, é a oportunidade da família se unir ainda mais para dar o suporte tão necessário ao adolescente.

As relaçôes familiares foram apontadas como relação íntima para todos os adolescentes, totalizando 39 pessoas citadas. O grau de parentalidade foram os pais, irmãos, avós, tios e madrasta. $\mathrm{O}$ que nos chama atenção nessa análise é que três adolescentes citaram seis pessoas cada um nesse círculo, mostrando que possuem várias pessoas da família muito próximas dando-lhes suporte. Por outro lado, nos preocupa o fato de um adolescente citar somente uma pessoa nessa relação íntima. Os demais adolescentes variaram entre duas a cinco pessoas.

Podemos constatar nas falas a seguir que o suporte prestado é expresso através do preparo da alimentação por algumas famílias:

Eles até fazem coisas para ele comer [...] Sim, até quando a gente vai visitar a casa de alguém eles geralmente já preparam alguma coisa para ele comer. (E3)

A gente não sai, a gente evita. A gente já não vai a aniversário nada. Ai um irmão meu convida, alguém convida, ai já sabe que ele tem diabetes, ai já compra uma agua com gás que ele gosta, um suco natural. (E7)

Muitos familiares desenvolvem formas de auxiliar os adolescentes a contornar situaçóes como as citadas acima, a fim de afetar o mínimo possível o bem-estar das crianças e adolescentes ${ }^{(4)}$. Porém, acaba ocorrendo grande limitação da vida social da família, e em alguns momentos é 
deixado de frequentar locais onde o filho poderia estar em contato com alimentos que náo pode mais comer ${ }^{(3)}$.

$\mathrm{Na}$ relação pessoal, nove adolescentes citaram 34 pessoas, sendo eles avós, tios, padrinhos, irmãos, primos e sobrinha. Um adolescente citou sete pessoas, os demais ficaram entre uma a seis pessoas citadas.

$\mathrm{Na}$ relação ocasional somente um adolescente citou a irmã. Chamou-nos atenção que o adolescente E9, com seis pessoas em sua relação íntima não citou nenhuma pessoas na relação pessoal e casual.

A participação familiar é fundamental para o êxito da aquisição de hábitos mais saudáveis por parte do adolescente diabético, que, ao compartilharem do apoio da família, sentiram-se motivados a persistir ${ }^{(4)}$.

A afirmação acima reforça o papel da família diante do adolescente com DM1, esse envolvimento parece estar acontecendo de forma discreta para alguns adolescentes, o que dificulta ainda mais a adoção do autocuidado.

Por outro lado percebemos que a rotina familiar acaba por alterar por completo a partir da nova realidade, muitas vezes necessitando ter o suporte das pessoas da família, porém na maioria dos relatos constatamos que a participação é pontual como nos casos do preparo de alguns alimentos, mas em sua maioria não há envolvimento:

Tem meu pai, minha mãe (a avó) mas eles não tem muito contato. Eles moram em baixo da minha casa e eu em cima. Não mudaram nada.(E6)

É de extrema relevância o papel dos familiares no cotidiano desses adolescentes, todas as atitudes e comportamento serão reproduzidos por eles, entendemos que a família muitas vezes sente-se sobrecarregada, mas sem dúvidas seu papel é de suma importância.

\section{Relações de amizade}

As relaçôes íntimas foram citadas por todos os adolescentes, totalizando 37 nomes, dois adolescentes citaram seis amigos cada um, os demais ficaram entre um e cinco amigos.

As relaçóes pessoais totalizaram 26 nomes, sendo que E9 elencou 11 amigos. Já nas relações ocasionais nenhum suporte foi identificado.

A literatura mostra que esse apoio envolve o fator emocional, que está relacionado ao fato dos amigos não tratarem com diferença os colegas diabéticos e ainda tentarem tranquilizá-los acerca da doença ${ }^{(5)}$.

O convívio com os amigos foi relatado como suporte negativo por grande parte dos familiares entrevistados:

\section{[...] ela come um pouquinho a mais do que deve [...]. Mas é na casa das amiguinhas né. (E4)}

Desta forma, pode-se pensar que o comportamento dos amigos, na visão dos familiares, influencia de forma negativa a vida dos adolescentes com DM, o que nos remete a questionar se estes amigos estão tentando tratar com igualdade seus amigos ou estes não percebem a necessidade do cuidado.

O depoimento a seguir destaca o medo da mãe em deixar a adolescente sair com suas amigas:

Outra coisa que talvez teria que ter uma vida normal como os outros adolescentes assim vamos dizer. Mas você sempre fica com aquele receio de quando ela sai e eu não estou do lado, eu sou muito máe coruja. (E5)

A relação com seus pares e amigos exerce um papel importante no desenvolvimento emocional do adolescente ${ }^{(6)}$.

Ao mesmo tempo em que esta máe fica insegura com o que poderá acontecer quando sua filha estiver com os amigos, percebe a necessidade de ela ter uma "vida normal", que ao seu entender isso não será possível longe dos amigos.

\section{Relações escolares}

Nas relações íntimas, cinco adolescentes identificaram 22 pessoas que lhes dão suporte, 
estes são os professores, diretores, coordenadores e amigos.

Nas relaçóes pessoais somente oito pessoas foram destacadas por quatro adolescentes, sendo eles os professores, diretores e coordenadores. Nas relaçóes ocasionais seis pessoas foram citadas por três adolescentes, os diretores e os coordenadores das escolas.

O ambiente escolar torna-se o principal local de convivência social do adolescente, onde eles acabam tendo que lidar com a doença frente à sociedade. É neste espaço também, que se percebe fortemente a intervenção de aspectos como a dieta imposta pela doença. Caracterizada pelos adolescentes como um espaço propício para o desenvolvimento de açóes de promoção à alimentação saudável ${ }^{(7)}$.

Porém os resultados nos mostram que a rede de suporte escolar é bastante fragilizada e que poucos encontram-se envolvidos no processo de cuidado aos adolescentes. Por outro lado, é um espaço amplo de convivência com colegas, professores e funcionários, todos precisam estar sensibilizados para fortalecer o autocuidado. As falas a seguir destacam o cuidado no preparo da alimentação:

Todo intervalo eu ganho a merenda diferenciada. (A9)

Tem o lanche separado dela, na escola. A gente levou um papel lá, comunicou lá, dai eles já tem esses cuidados. (E8)

Por um lado cuidado com alimentação é percebido como fator positivo, porém uma adolescente percebe a insegurança e o medo dos professores ao ter que enfrentar situaçôes como a hiperglicemia ou a hipoglicemia, facilmente identificadas pelo adolescente que já sabe como manejá-la:

Eles têm medo. Cada vez que tá alta (a glicemia) eles querem ligar para minha mãe, e é isso que eu não gosto. Dai atrapalha a minha mãe. [...] Eu tenho a minha consciência que se eu tomar a insulina vai baixar. (A2)
Ao perceber o relato da adolescente, entendemos a preocupaçáo dos professores frente a essa situação, pois a adolescente tem um histórico de frequentes internaçóes em UTI devido à descompensação da glicemia.

A correlação negativa encontrada entre a dimensão ambiente escolar e o número de hospitalizaçôes também permitem reflexôes importantes sobre o papel da escola e dos professores no cotidiano dos adolescentes com DM1 ${ }^{(8)}$.

Uma forma de sanar ou amenizar esse "medo" dos professores e direção das escolas é os profissionais de saúde e familiares estarem em frequente contato com a escola, uma relaçáo próxima e de suporte auxiliará no manejo das crises e esclarecimento de dúvidas.

\section{Relações comunitários}

As relações comunitárias foram citadas por sete adolescentes, totalizando 13 pessoas na relação íntima, sendo essas pessoas médicos, enfermeira, irmãos da igreja, vizinha, mãe de amiga, cunhado, tias, amiga, ex-professora, ex-merendeira da escola e coordenadora do estágio.

Cabe salientar que tais práticas, afiliaçôes e crenças estão presentes na sociedade como um todo e, no campo da saúde, influenciam tanto os doentes e suas famílias quanto os profissionais de saúde que os assistem ${ }^{(9)}$.

$\mathrm{Na}$ relação pessoal três adolescentes identificaram sete pessoas, a enfermeira e os irmãos da igreja. E nenhuma pessoa citada na relação ocasional.

A presença da vida religiosa das famílias foi percebida por boa parte dos sujeitos como suporte positivo, trazendo alento e esperança:

Ela estava magra [...] cada dia sumindo, e a gente tem culto às quartas-feiras, eu chorava lá no culto pedindo pelo amor de Deus, que o pessoal orasse para que a gente descobrisse o que ela tinha. (Avô 8)

Nós acreditamos, nós temos fé que ela vai ser curada. Que Deus vai fazer um milagre na 
vida dela, isso é fato, isso a gente sabe [...] ainda não aconteceu. (E10)

As crenças dessas famílias em algo maior que irá amenizar sua dor ou até mesmo fazer um milagre é o que muitas vezes acaba minimizando o sofrimento diante das dificuldades que a doença traz.

Houve o relato de uma família que diante do desespero para "curar" sua filha buscou na "garrafada" ajuda:

Alguém ensinou uma garrafada também, era leite condensado com vinho e o figado né batido no liquidificador. (Avó 8)

Deve-se alertar para o fato de que algumas pessoas do estudo utilizaram terapias populares para cuidar-se e muitas vezes valorizaram mais estas práticas do que as indicaçóes de medicamentos ${ }^{(10)}$.

$\mathrm{O}$ relato vem ao encontro com a literatura, a família acabou fazendo uso do conhecimento popular para tratamento da filha/neta, porém como o diagnóstico do diabetes ainda não havia se confirmado acabou prejudicando a adolescente ainda mais. Contudo, não podemos desconsiderar que o uso de plantas medicinais auxilia no tratamento de algumas doenças, mas devemos informar aos familiares que, em alguns momentos, esse uso prejudica o tratamento de seus filhos/netos.

Ao mesmo tempo em que se busca na religiáo suporte, ocorre o contrário para um pai ao descobrir a doença do filho:

Aborreci! Porque antes né, a gente seguia muito a minha mãe principalmente e fazia tudo certinho as coisa (referindo-se ao frequentar a igreja). O filho com diabetes, a mulher com diabetes o outro filho surdo, ah pelo amor de Deus, ele não está me ajudando, então eu também não preciso ajudar ele. (E9)

A esperança de que ao frequentar a religião náo iria permitir a chegada da doença acaba por afastar este pai da igreja, pois a doença chegou para três pessoas de sua família em pouco espaço de tempo, quando este deposita toda sua fé e ao se decepcionar, tira-o dos trilhos e acaba causandolhe revolta.

\section{CONCLUSÃO}

Constatamos que para alguns adolescentes e seus familiares as redes de suporte existentes se fortaleceram, porém para outros, ficou evidenciado a falta dessa rede, dificultando ainda mais o enfrentamento da doença. Mas, são mecanismos importantes de suporte social e primordial no cuidado à saúde desses adolescentes.

Dessa forma, acreditamos que o autocuidado apoiado possibilite acionamento das redes de suportes disponíveis, sejam elas familiares, escolares, dos serviços de saúde, religiosos entre outros e, assim, envolva todos no plano de cuidado aos adolescentes e apoio aos familiares.

\section{REFERÊNCIAS}

1. Tavares JSC, Rocha AARM. Redes sociais de suporte: ponte entre a família e outros contextos da atenção. In:Trad LAB, Jorge MSB, Pinheiro R, Mota CS, Rocha AGRM, organizadores. Contextos, parcerias e itinerários na produção do cuidado integral: diversidade e interseçôes. Rio de Janeiro: CEPESC/ABRASCO; 2015. p. 135-147.

2. Nascimento LC, Rocha SMM, Hayes VE. Contribuiçóes do genograma e do ecomapa para o estudo de famílias em enfermagem pediátrica. Texto contexto enferm. 2005; 14 (2): 280-6.

3. Corrêa A, Franco S, Demário RL, Santos EF. Diabetes Mellitus tipo 1: vivência dos pais em relação à alimentação de seu filho. BrazilianJournalofFood \&Nutrition/Alimentos e Nutrição. 2012; 23(4):632-637.

4. Leal DT, Fialho FA, Andrade F, Dias IMAV, Nascimento L, Arruda WC. A vivência dos familiares de crianças e adolescentes portadores de diabetes mellitus tipo 1. RevEletrEnf[Internet]. 2012 [acesso em 2014 Fev 10]; 14 (1): 189-96. 
Disponível em: https://www.fen.ufg.br/fen_ revista/v14/n1/pdf/v14n1a22.pdf

5. Fragoso LVC, Lima AKG, Damasceno MMC. Vivências cotidianas de adolescentes com diabetes mellitus tipo 1 . Texto contexto enferm. 2010;19(3): 443-51.

6. Damiāo EBC, FabriLRO, Dias,VC. O adolescente e o diabetes: uma experiência de vida. Acta paulenferm. 2010; 23(1): 41-7.

7. Silva DCDA, Frazão IDS, Osório MM, Vasconcelos MGLD. Percepção de adolescentes sobre a prática de alimentação saudável. RevCiênc. saúde coletiva. 2015; 20(11): 3299-308.

8. Perez LC. Adolescentes com diabetes mellitus tipo I: resiliência, qualidade de vida e suporte social. [dissertação]. Porto Alegre (RS): Universidade Federal do Rio Grande do Sul; 2013.

9. Martins AJ, Cardoso MHCA, Llerena Júnior JC, Moreira MCN. A concepção de família e religiosidade presente nos discursos produzidos por profissionais médicos acerca de crianças com doenças genéticas. RevCiênc. saúde coletiva. 2012; 17(2): 545-553.

10. Taddeo PS, Gomes KWL, Caprara A, Gomes AMA, Oliveira GC, Moreira TM. Acesso, prática educativa e empoderamento de pacientes com doenças crônicas. RevCiênc. saúde coletiva. 2012; 17(11): 2923-30.

Recebido em: 29/07/2018.

Publicado em: 03/12/2018. 